\title{
Erratum to: Decellularized Extracellular Matrices in Bone Tissue Engineering: From Cells to Tissues. Mini-Review
}

\author{
Azam Bozorgi Zarrini ${ }^{a}$, Maryam Bozorgi ${ }^{b}$, Mozafar Khazaei ${ }^{b}$, and Mansooreh Soleimani ${ }^{c, *, * *}$ \\ ${ }^{a}$ Department of Tissue Engineering and Regenerative Medicine, School of Advanced Technologies in Medicine, \\ Iran University of Medical Sciences, Tehran, Iran \\ ${ }^{b}$ Fertility and Infertility Research Center, Health Technology Institute, Kermanshah University of Medical Sciences, \\ Kermanshah, Iran \\ ${ }^{c}$ Cellular and Molecular Research Center, Iran University of Medical Sciences, Tehran, Iran \\ *e-mail: mansourehsoleimani@gmail.com \\ **e-mail: soleimani.m@iums.ac.ir \\ Submitted April 14, 2021; accepted for publication April 14, 2021
}

DOI: $10.1134 / \mathrm{S} 1990519 X 21030147$

Affiliation of the first author should read as follows:

${ }^{a}$ Department of Tissue Engineering and Regenerative Medicine, School of Advanced Technologies in Medicine, Iran University of Medical Sciences, Tehran, Iran

The original article can be found online at https://doi.org/10.1134/S1990519X20060127 